\title{
Nanofluid-based Minimum Quantity Lubrication (MQL) Face Milling of Inconel 625
}

\author{
P. Singh ${ }^{1 *}$, J. S. Dureja ${ }^{1}$, H. Singh ${ }^{2}$ and M. S. Bhatti ${ }^{3}$ \\ ${ }^{1}$ Mechanical Engineering Department, Punjabi University, Patiala-147002, \\ Punjab, India. \\ ${ }^{2}$ Department of Mechanical Engineering, Guru Nanak Dev Engineering College, \\ Ludhiana- 141006, Punjab, India. \\ ${ }^{3}$ Department of Botanical and Environmental Sciences, Guru Nanak Dev University, \\ Amritsar, Punjab, India. \\ *Email: pargatucoe@gmail.com \\ Mobile: +91 9872155577, Fax: +91-175-3046333.
}

\begin{abstract}
Machining with minimum quantity lubrication (MQL) has gained widespread attention to boost machining performance of difficult to machine materials such as $\mathrm{Ni}-\mathrm{Cr}$ alloys, especially to reduce the negative impact of conventional flooded machining on environment and machine operator health. The present study is aimed to evaluate MQL face milling performance of Inconel 625 using nano cutting fluid based on vegetable oil mixed with multi-walled carbon nanotubes (MWCNT). Experiments were designed with 2-level factorial design methodology. ANOVA test and desirability optimisation method were employed to arrive at optimised milling parameters to achieve minimum tool wear and machined surface quality. Experiments were performed under nanoparticles based minimum quantity lubrication (NMQL) conditions using different weight concentrations of MWCNT in base oil: 0.50, 0.75, 1, 1.25 and 1.5 wt. \%; and pure MQL environment (without nanoparticles). The optimal MQL milling parameters found are cutting speed: $47 \mathrm{~m} / \mathrm{min}$, table feed rate: $0.05 \mathrm{~mm} /$ tooth and depth of cut: $0.20 \mathrm{~mm}$. The results revealed improvement in the surface finish (Ra) by $17.33 \%$ and reduction in tool flank wear (VB) by $11.48 \%$ under NMQL face milling of Inconel 625 with $1 \%$ weight concentration of MWCNT in base oil compared to pure MQL machining conditions.
\end{abstract}

Keywords: Minimum quantity lubrication, nanoparticles, multi-walled carbon nanotubes; Inconel 625; face milling; tool wear; surface roughness

\section{INTRODUCTION}

Nowadays, industries and governments are encouraging the development of environmentfriendly machining system to give clean production which helps in to reduce pollution caused by cutting fluids (flooded coolant) [1]. Dry machining is a better alternative for environmentally friendly and low-cost machining (because cutting fluid not utilised). However, in the milling process, the adverse effects of dry machining are much higher in the case of difficult to machine material like Inconel, stainless steel etc., because they exhibit poor machinability.

Machining under minimum quantity lubrication (MQL) conditions has gained widespread attention owing to its low oil utilisation in metal cutting operations along with improved machining performance. Consumption of cutting fluid (oil) in MQL is quite 
low: $50-150 \mathrm{ml} / \mathrm{h}$; compared to $950-1200 \mathrm{l} / \mathrm{h}$ in conventional or flood cooling conditions [2-4]. MQL technique shows superior physical and tribological characteristics in the cutting zone while machining of sticky materials [5, 6]. Moreover, MQL system makes machining environment eco-friendly by minimising worker health hazard issues and reduction in production cost up to 15\% [7]. Amrita et al. [8] revealed MQL machining leads to a reduction in tool flank wear by $71 \%$, surface roughness by $30 \%$, cutting forces by $54 \%$ and cutting temperature by $25 \%$ compared to flooded/wet conditions during machining of AISI 1040 steel. Sun et al. [9] observed improved end milling performance of titanium Ti-6Al-4V under MQL due to enhanced lubrication-cooling effect compared to the dry and flooded environment. Singh et al. [10] reported a reduction in tool flank wear (VB) by $40 \%$ during MQL milling of Inconel 718 compared with flooded conditions. Werda et al. [11] suggested that utilisation of MQL, improves the tool life of flank face by $28.5 \%$ and $11 \%$ of rake face, compared to dry milling of X100CrMoV5 mould steel. Their results also revealed less adhesion of materials on the flank face of the cutting tool compared to dry machining.

The wide acceptability of MQL has paved the way for the development of newer technologies that complement with the existing MQL machining procedure, for e.g. the inclusion of nanoparticles in MQL lubricant; results in new NMQL technique (Nanofluid minimum quantity lubrication). Suspension of nanoparticles in cutting fluid called as nanofluids reduce friction in cutting zone at elevated temperature. In addition, the high heat-carrying capacity of nanoparticles enhances the effectiveness of NMQL during machining of difficult-to-cut materials [12-15]. According to Sharma et al. [16], nanofluids not only increase the thermal conductivity, tool life and surface finish but also decreases the cutting zone temperature and cutting forces. Many researchers have noticed that as the concentration of nanoparticles increased in the base fluid, it leads to the improved thermal conductivity of nanofluid. Vajjhay and Das [17] experienced a $22.4 \%$ increase in thermal conductivity with the addition of $6 \%$ wt. of $\mathrm{Al} 2 \mathrm{O} 3$ nanoparticles concentration in a base oil. Similarly, Choi et al. [18] also examined enhanced heat conductivity by $150 \%$ when multi-walled carbon nanotubes were reinforced in the base cutting oil. Setti et al. [19] observed that $\mathrm{Al} 2 \mathrm{O} 3$ nano-fluid with MQL proves to be an efficient technique for flushing of chips from grinding zone and also helps to reduce friction in machining zone during machining of Ti-6Al-4V. Eltaggaz et al. [20] claimed enhanced tool life at cutting speed of $120 \mathrm{~m} / \mathrm{min}$ and $0.2 \mathrm{~mm} / \mathrm{rev}$ feed rate with $\mathrm{Al} 2 \mathrm{O} 3$ nanoparticles under MQL compared to classical MQL. This is due to improved wettability, convection and conduction characteristics of nanofluid MQL.

Reddy and Rao [21] claimed utilisation of molybdenum disulfide nanoparticles $(\mathrm{MoS} 2)$, results in better tribological behaviour due to reduced coefficient of friction at work- tool-chip interface under NMQL end milling of AISI 1045 steel. The use of graphite and aluminium oxide nanoparticles in base oil helps to reduce cutting forces, chip thickness and flank wear of tool, thereby results in improved tool life as studied by Amrita et al. [8] and Khandekar et al. [22] during turning of alloy steels (AISI 1040 and AISI 4340, respectively) under NMQL conditions. The application of hybrid-based nanofluids reduces cutting zone temperature and tool wear by $27.36 \%$ and $11 \%$ respectively while turning of AISI 304, as compared to alumina-based single nanofluid [23]. Rahmati et al. [24] studied the effect of MoS2 nano-fluid during machining of Al6061-T6 alloy and results showed a considerable reduction in surface roughness and cutting forces. Similarly, Rao and Satyanarayana [25] performed NMQL (CNT based nano-fluid) turning experiments to find out the flank wear and temperatures in cutting zone. Results suggested, when CNT concentration is increased, the nodal temperature decreases. 
Krishna et al. [26] observed that the utilisation of nano-fluid (carbon nanotubes mixed in coconut oil) MQL help in to reduce cutting temperature, cutting force, surface roughness and tool wear. According to Hegab et al. [27], nanofluid based on 2 wt. \% MWCNT (multi-walled carbon nanotubes), results in decreasing power consumption by $11.5 \%$ and tool flank wear by $45 \%$ in MQL machining of Ti-6Al-4V alloy compared to pure MQL (without nanoparticles).

Singh et al. [28] noticed a significant reduction in tool wear by $18.17 \%$ and $4.54 \%$; and improvement in the surface finish by $55.58 \%$ and $5.48 \%$; compared to dry and flooded machining, respectively, during turning of Inconel 625 under nano-fluid MQL conditions. Similarly, tool flank wear was reduced by $32.26 \%$ and $9.68 \%$; and improvement in the surface finish by $34.72 \%$ and $7.59 \%$ compared to dry and flooded machining respectively, during nanofluid MQL turning of stainless steel 304 [29]. Similarly, according to Singh et al [30], utilisation of nano-fluid (multi-walled carbon nanotube enhanced with soybean oil) with MQL gives superior results during face milling of stainless steel 304. The results revealed that improvement in nanofluid MQL over dry, flooded and pure MQL conditions by $7.45 \%, 2.08 \%$ and $5.15 \%$ respectively, in terms of tool flank wear and $54.10 \%, 34.43 \%$ and 39.34 respectively, in terms of surface finish. In addition, tool flank wear characterisation indicated less adhesion and abrasion marks on tool face while machining with nanofluid MQL compared to dry and flood conditions.

Sharma et al. [31] explored turning performance of AISI 1040 steel using $\mathrm{Al} 2 \mathrm{O} 3$ nanoparticles with MQL. Their finding revealed lesser cutting forces by $28.6 \%, 29.2 \%$ and $59.1 \%$ compared to wet, mist and dry conditions, respectively. Minh et al. [32] reported tool life improvement up to $177 \%$ during hard milling of hardened 60Si2Mn steel using NMQL (A12O3 nanoparticle with soybean oil at $0.5 \mathrm{wt} . \%$ ) compared to pure MQL. Moreover, the utilisation of NMQL also decrease the cutting forces and surface roughness. Kursuncu and Yaras [1], revealed improvement in surface roughness: 52\%, $38 \%$; and tool life: $110 \%, 50 \%$; in ethylene glycol cutting fluid containing 5\% volumetric concentration of boric and borax acid, respectively, during MQL milling of AISI O2. Literature survey indicates different types of solid nanoparticles viz. silicon dioxide (Sio2), molybdenum disulfide (MoS2) and carbon nanotubes (CNTs) etc., when added into base cutting oil; gives promising results in machining operations [33].

Wide application of super-alloy Inconel 625 is found in marine, oil, aerospace and gas industries due to its excellent properties: high thermal strength, toughness and resistance to corrosion [34, 35]. But, machining of Inconel 625 is very challenging because of its high abrasiveness, chemical reactive, high hardness and poor thermal conductivity which make it difficult to machine material. Therefore, various types of cutting tools have been used e.g. ceramic tools, cemented carbide, coated or uncoated, which show high tool flank wear during machining of Inconel alloys, thus results in lesser tool life and poor surface finish [36, 37]. The utilisation of nano-fluid with MQL is highly capable of reducing the temperature in cutting zone during machining of nickel-based alloys due to increased thermal conductivity [6].

The literature review also highlighted that the majority of work done on pure MQL and NMQL using various nanoparticles viz. $\mathrm{SiO} 2, \mathrm{MoS} 2, \mathrm{CNT}$ etc. to attain superior machining performance. However, no literature is available on face milling of nickel-base alloy: Inconel 625 under NMQL conditions using soybean oil mixed with MWCNT (multi-walled carbon nanotubes) based nano cutting fluid. Therefore, the present research was focused to discover the performance of MQL and NMQL on the basis of Ra and VB, during face milling of Inconel 625. 


\section{EXPERIMENTAL DETAILS}

Inconel 625 with dimension of $100 \times 50 \times 50 \mathrm{~mm}$ was selected as work material for face milling having chemical composition (wt.\%) of Ni-62.62,Cr-20.64, Fe-3.29, Mo-8.33, Si0.26, Co-0.30, C-0.04, Nb-3.67, P-0.012, Al-0.037, Ti-0.23, Mn-0.31, S-0.01. VF15TFPVD (Al/Ti)N coated cutting tool was utilised for milling operation. The experiments were conducted on CNC milling machine (Make: Kent, Model: KMV 11VC) having specifications of $8000 \mathrm{rpm}$ (max.), X-Y-Z travel: 1100, 600 and $600 \mathrm{~mm}$, respectively, maximum work table load: $900 \mathrm{~kg}$, cutter diameter: $50 \mathrm{~mm}$. Initially, the upper layer of Inconel 625 was face milled to remove the oxidised layer. Fresh cutting tool edge was used for each experiment.

\section{Nanoparticles Based MQL (NMQL)}

In the present study, MQL setup (Make: NOGA) was imported from Israel, having two inlet supply pipes: for compressed air and cutting oil along with two discharge adjustable nozzles to deliver the aerosol mixture to cutting zone in the form of fine mists. In MQL, lubrication action is given by cutting fluid whereas cooling action is provided by compressed air. Controllable parameters in MQL: base oil, base oil density, compressed air pressure, the quantity of cutting fluid (oil), nozzle angle (approximate) and nozzle distance (approximate) are mentioned in Table 1. The range of parameters was finalized through relevant literature and also by conducting pilot experiments to find the optimal combination of MQL parameters. Soybean oil was used as base cutting fluid because it is environment-friendly, biodegradable, non- hazardous to the machine operator and provides high viscosity index (viscosity and density at $25^{\circ} \mathrm{C}: 48.0 \mathrm{cP}$ and $0.917 \mathrm{~g} / \mathrm{ml}$ ) [28]. A cutting fluid with a higher viscosity index provides superior lubrication performance. To improve its thermal conductivity, multi-walled carbon nanotubes (MWCNT) were mixed using ultrasonication and magnetic stirring process. MWCNT were selected owing to its superior properties: high thermal conductivity-3000 W/m.k and high mechanical stability, compared to other nanoparticles. Figure 1 shows the MQL setup attached to face milling machine with two discharge nozzles to achieve better penetration of lubricant in the cutting zone.

Table 1. MQL parameters.

\begin{tabular}{lc}
\hline Base oil and density of base oil & Soybean, $0.917 \mathrm{~g} / \mathrm{ml}$ at $25^{\circ} \mathrm{C}(\mathrm{l})$ \\
\hline Compressed air pressures (bar) & 5 \\
Oil quantity (ml/hour) & 75 \\
Nozzle angle approximate $\left({ }^{\circ}\right)$ & 45 \\
Nozzle distance (approximate) from interface & 50 \\
zone $(\mathrm{mm})$ & \\
\hline
\end{tabular}

\section{Design of Experiment}

In the first design phase, experiments were designed using 2-level factorial design approach. The selected face milling parameters were: cutting speed $(30,40,50 \mathrm{~m} / \mathrm{min})$, table feed rate $(0.05,0.075,0.1 \mathrm{~mm} /$ tooth $)$ and depth of cut (DOC): $(0.2,0.3,0.4 \mathrm{~mm})$ during machining of Inconel 625 under MQL conditions. Total 11 experiments (Table 2) were performed including eight factorial points $( \pm 1$ level) and centre points $(0$ level - 
repeated thrice to check machine repeatability). Ra was evaluated by surface roughness tester (Make: Mitutoyo Surftest: SJ-201) and tool flank wear (VB) of used cutting edges was observed with tool maker's microscope (Make: Metzer toolmaker's microscope). The criteria followed to stop machining test were:

i. $\quad \mathrm{VB} \geq 0.3 \mathrm{~mm}(300 \mu \mathrm{m})$ (as per ISO 8688-2) [34].

ii. $\quad \mathrm{Ra} \geq 1.6 \mu \mathrm{m}[38]$.

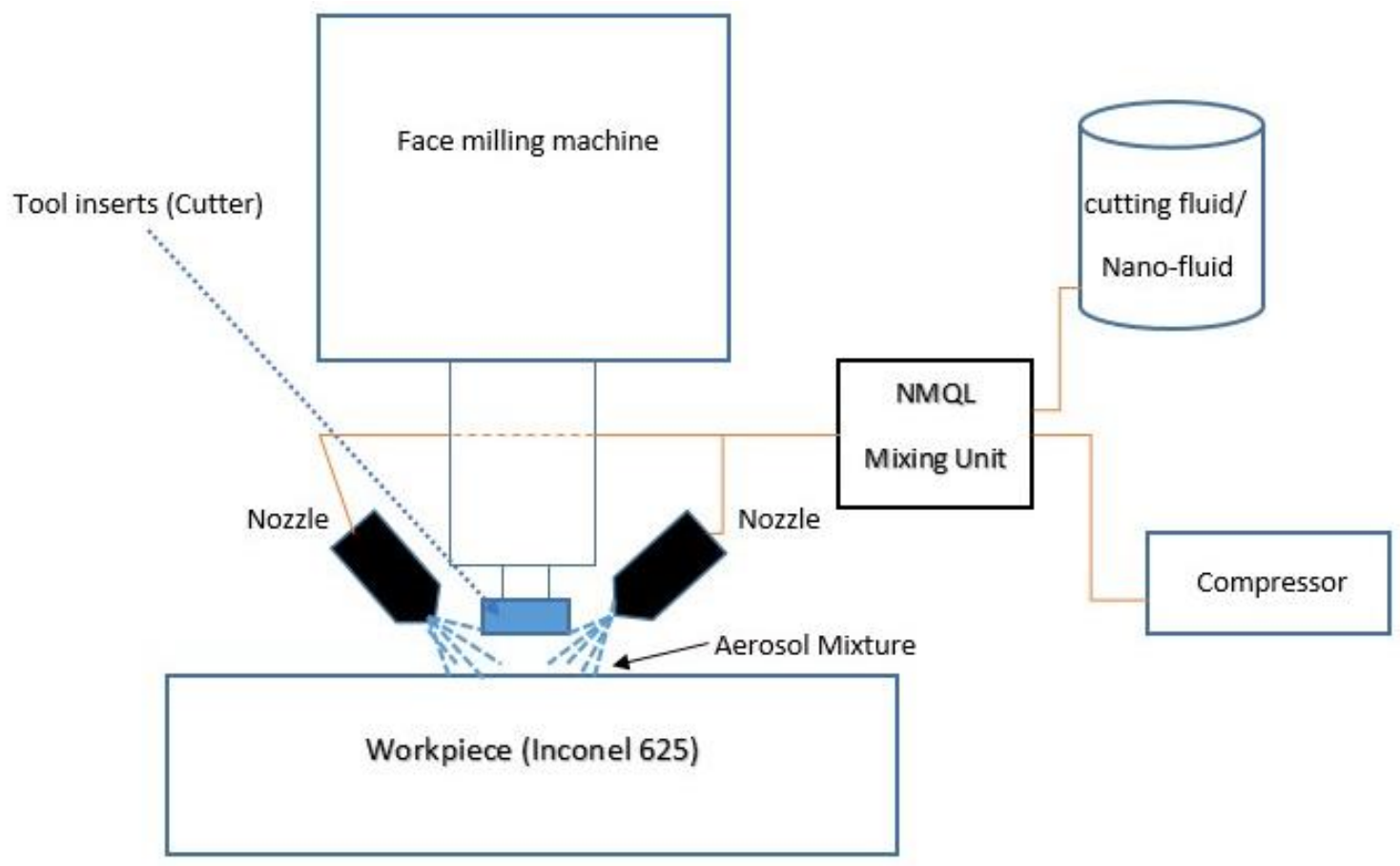

Figure 1. MQL setup on face milling machine.

Table 2. Plan of experiments.

\begin{tabular}{lccccc}
\hline $\begin{array}{l}\text { S. } \\
\text { No }\end{array}$ & $\begin{array}{c}\text { Speed } \\
(\mathrm{m} / \mathrm{min})\end{array}$ & $\begin{array}{c}\text { Table feed } \\
(\mathrm{mm} / \text { tooth })\end{array}$ & $\begin{array}{c}\text { Depth of cut, } \\
\text { DOC }(\mathrm{mm})\end{array}$ & $\begin{array}{c}\text { Surface roughness, } \\
\mathrm{Ra}(\mu \mathrm{m})\end{array}$ & $\begin{array}{c}\text { Flank wear, } \\
\text { VB }(\mu \mathrm{m})\end{array}$ \\
\hline 1 & 30 & 0.05 & 0.4 & 1.25 & 230 \\
2 & 50 & 0.1 & 0.2 & 1.31 & 185 \\
3 & 40 & 0.075 & 0.3 & 0.96 & 257 \\
4 & 40 & 0.075 & 0.3 & 1.03 & 240 \\
5 & 30 & 0.1 & 0.2 & 1.49 & 230 \\
6 & 30 & 0.05 & 0.2 & 0.96 & 225 \\
7 & 30 & 0.1 & 0.4 & 1.21 & 210 \\
8 & 50 & 0.1 & 0.4 & 0.95 & 240 \\
9 & 50 & 0.05 & 0.4 & 1.35 & 265 \\
10 & 40 & 0.075 & 0.3 & 0.89 & 185 \\
11 & 50 & 0.05 & 0.2 & 1.02 & \\
\hline
\end{tabular}

The statistical significance of various machining parameters was evaluated through the ANOVA test. Mathematical models were fitted to data by multipleregression analysis. Optimal conditions were found through RSM (response surface 
methodology) based desirability function optimisation to attain minimum surface roughness $(\mathrm{Ra})$ and tool flank wear (VB). In the second design phase, experiments were conducted under NMQL environment with different weight concentrations of MWCNT in base oil: $0.50,0.75,1,1.25$ and $1.5 \mathrm{wt}$. \% to compare face milling performance of Inconel 625 under MQL and NMQL on the basis of Ra and VB.

\section{RESULTS AND DISCUSSION}

\section{Modelling of Ra and VB}

A quadratic model was found as the best fit model for both Ra and VB. The predicted models for Ra and VB are considered to be statistical significant $(\mathrm{p}<0.05)$. ANOVA results (Table 3 and Table 5) revealed that $\mathrm{F}$-value for $\mathrm{Ra}=55.89$ and $\mathrm{VB}=18.06$ is quite large, thereby giving a good significance of fitted models for Ra and VB. In case of Ra: $\mathrm{A}, \mathrm{B}, \mathrm{AB}, \mathrm{BC}$ and $\mathrm{A}^{2}$ are the parameters contributing significantly to fitted model, whereas, for VB: A, C, AC and $\mathrm{B}^{2}$ are the significant parameters. The lack of fit F-value for $\mathrm{Ra}(0.3184)$ and VB (0.370) indicates that the "Lack of Fit" is non-significant, as expected.

$$
\begin{aligned}
& \mathrm{Ra}=+2.12157-0.17232 * \text { speed }+32.80000 * \text { feed }+7.32551 * \mathrm{DOC}-0.30 \\
& * \text { speed } * \text { feed }-63 * \text { feed } * \mathrm{DOC}+2.38909 \mathrm{E}-003 * \text { speed }^{2}-4.40724 * \mathrm{DOC}^{2} \\
& \mathrm{VB}=+136.85098-5.03518 * \text { speed }+7495.49062 * \text { feed }-466.25589 * \mathrm{DOC}+ \\
& 14.37500 * \text { speed } * \text { DOC }-50136.60414 * \text { feed }^{2}
\end{aligned}
$$

Table 3. ANOVA results for Ra.

\begin{tabular}{lcccccc}
\hline Source & $\begin{array}{c}\text { Sum of } \\
\text { squares }\end{array}$ & DF* & $\begin{array}{c}\text { Mean } \\
\text { square }\end{array}$ & F value & Prob > F & Remarks \\
\hline Model & 0.469 & 7 & 0.067 & 55.899 & 0.001 & Significant \\
A-Cutting speed & 0.012 & 1 & 0.012 & 9.913 & 0.035 & significant \\
B-Table feed & 0.018 & 1 & 0.018 & 15.071 & 0.018 & significant \\
C-DOC & 0.000 & 1 & 0.000 & 0.140 & 0.727 & not significant \\
AB & 0.045 & 1 & 0.045 & 37.573 & 0.004 & significant \\
BC & 0.198 & 1 & 0.198 & 165.698 & 0.000 & significant \\
A $^{2}$ & 0.186 & 1 & 0.186 & 155.089 & 0.000 & significant \\
C $^{2}$ & 0.006 & 1 & 0.006 & 5.278 & 0.083 & not significant \\
Residual & 0.005 & 4 & 0.001 & & & \\
Lack of Fit & 0.002 & 3 & 0.001 & 0.318 & 0.826 & not significant \\
Pure Error & 0.002 & 1 & 0.002 & & & \\
Cor Total & 0.473 & 11 & & & & \\
\hline
\end{tabular}

*Degree of freedom

Table 4 and Table 6 show a summary of the statistical model for Ra and VB. The values of predicted $\mathrm{R}^{2}$ for $\mathrm{Ra}$ and VB are: 0.9181 and 0.7291 respectively, represent a close association with adjusted $\mathrm{R}^{2}$ values: $\mathrm{Ra}=0.9721$ and $\mathrm{VB}=0.8857$, which further validates fitted models. Adequate precision values $(\mathrm{Ra}=21.60$ and $\mathrm{VB}=13.63)$ suggest that developed model equations through multiple regression analysis, are significant within the selected range of parameters. Moreover, comparative lower values of 
coefficient of variation $(\mathrm{Ra}=3.003$ and $\mathrm{VB}=3.636)$ validate the reliability and precision of conducted experiments. The regression model equations obtained for Ra and VB, are shown in Eq. (1) and Eq. (2).

Table 4. ANOVA statistics for Ra.

\begin{tabular}{lccc}
\hline Std. Dev. & 0.035 & $\mathrm{R}^{2}$ & 0.990 \\
\hline Mean & 1.153 & Adj. $\mathrm{R}^{2}$ & 0.972 \\
C.V. \% & 3.003 & Pred. $\mathrm{R}^{2}$ & 0.918 \\
PRESS & 0.039 & Adequate precision & 21.604 \\
\hline
\end{tabular}

Table 5. ANOVA results for VB

\begin{tabular}{lcccccc}
\hline Source & $\begin{array}{c}\text { Sum of } \\
\text { squares }\end{array}$ & DF* & $\begin{array}{c}\text { Mean } \\
\text { square }\end{array}$ & F value & Prob > F & Remarks \\
\hline Model & 6192.77 & 5 & 1238.55 & 18.060 & 0.0015 & Significant \\
A-Cutting speed & 494.78 & 1 & 494.78 & 7.215 & 0.0362 & significant \\
B-Table feed & 3.125 & 1 & 3.125 & 0.046 & 0.838 & not significant \\
C-DOC & 1120.29 & 1 & 1120.29 & 16.335 & 0.0068 & significant \\
AC & 1653.13 & 1 & 1653.13 & 24.105 & 0.0027 & significant \\
B $^{2}$ & 2437.84 & 1 & 2437.84 & 35.547 & 0.001 & significant \\
Residual & 411.482 & 6 & 68.5803 & & & \\
Lack of Fit & 266.982 & 5 & 53.3964 & 0.370 & 0.8391 & not significant \\
Pure Error & 144.5 & 1 & 144.5 & & & \\
Cor Total & 6604.25 & 11 & & & & \\
\hline
\end{tabular}

*Degree of freedom

Table 6. ANOVA statistics for VB.

\begin{tabular}{lccc}
\hline Std. Dev. & 8.281 & $\mathrm{R}^{2}$ & 0.937 \\
\hline Mean & 227.75 & Adj. $\mathrm{R}^{2}$ & 0.885 \\
C.V. \% & 3.636 & Pred. $\mathrm{R}^{2}$ & 0.729 \\
PRESS & 1788.958 & Adequate precision & 13.630 \\
\hline
\end{tabular}

\section{Influence of Milling Parameters on Ra}

3D surface graphs from RSM were plotted to evaluate the effect of input milling parameters on VB and Ra. Figure 2(a) describes the effect of table feed and cutting speed on surface roughness. $\mathrm{Ra}$ is maximum at a table feed rate of $0.10 \mathrm{~mm} /$ tooth. This is due to the fact that high feed rate results in the generation of high cutting forces at chip-toolwork interface zone. When feed rate and cutting speed are increased, high vibration and temperature are produced in the cutting zone; consequently leads to higher surface roughness. Moreover, according to machining science of metal cutting: $R a=f^{2} / 32 r$, surface roughness is mostly influenced by table feed rate [39]; where, $r=$ nose radius and $\mathrm{f}=$ feed rate. When cutting speed increases from 30 to $40 \mathrm{~m} / \mathrm{min}$, surface roughness start decreasing and reach a minimum at $40 \mathrm{~m} / \mathrm{min}$., as also experienced by Bin et al. [40]. However, when the cutting speed is further increased from 40 to $50 \mathrm{~m} / \mathrm{min}$, surface roughness shows an increasing trend. Sonawane and Joshi [37] also experienced similar behaviour of surface roughness variation with the change of machining parameter during 
milling of Inconel 718. The optimum value of surface roughness is obtained as $0.96 \mu \mathrm{m}$ at cutting speed $=40 \mathrm{~m} / \mathrm{min}$. and table feed $=0.05 \mathrm{~mm} /$ tooth.

Figure 2(b) shows the influence of depth of cut (DOC) and table feed rate on Ra. Minimum surface roughness is obtained at DOC $=0.30 \mathrm{~mm}$ and table feed rate $=0.05$ $\mathrm{mm} /$ tooth. With an increase in table feed rate and DOC, Ra increases due to high friction developed at the tool-chip interface, increased chip area, increased temperature and cutting forces. $\mathrm{Lu}$ et al. [41] reported similar variation in surface roughness ( $\mathrm{Ra}$ ) with the change in DOC and table feed rate during micro-milling of Inconel 718. Similarly, Yazid et al. [42] found a similar trend for Ra while machining of Inconel 718 with PVD coated carbide cutting tool.

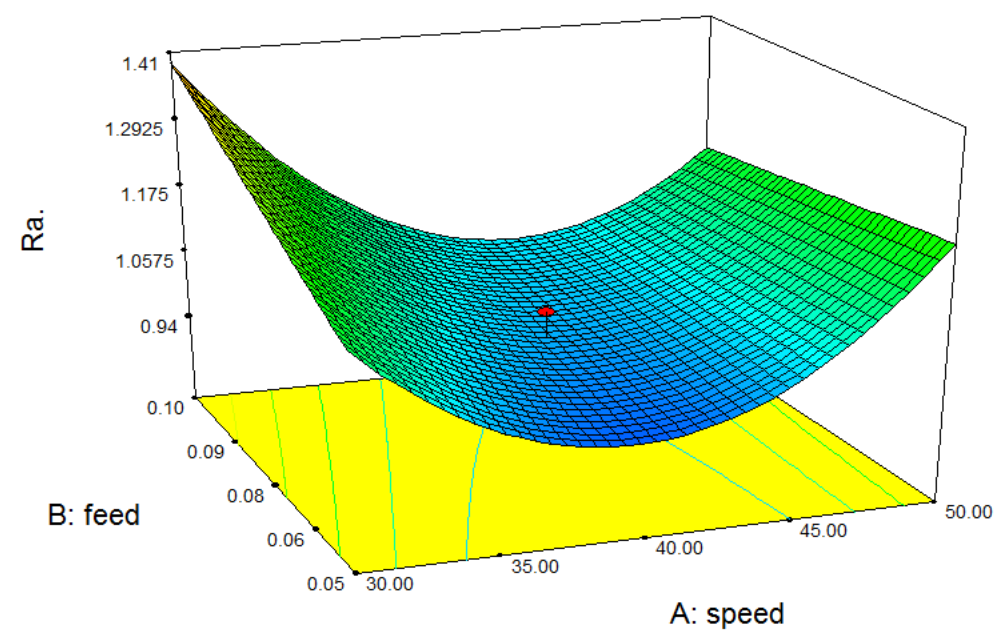

(a)

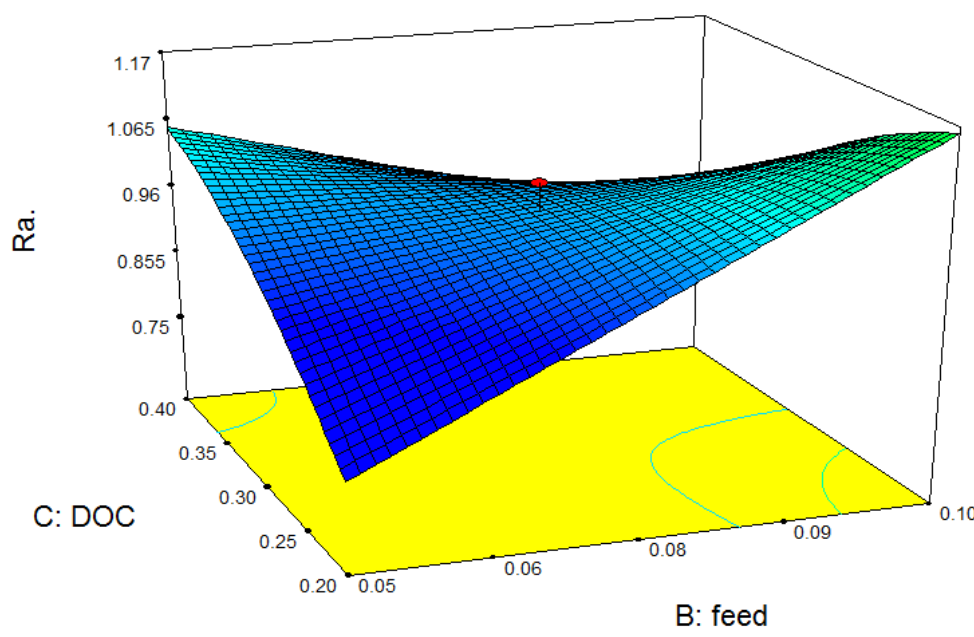

(b)

Figure 2. Influence of (a) cutting speed and table feed and; (b) table feed and depth of cut (DOC) on Ra.

\section{Influence of Milling Parameters on Tool Flank Wear (VB)}

Figure 3 depicts the influence of cutting speed and depth of cut (DOC) on tool flank wear 
(VB). At low DOC $=0.2 \mathrm{~mm}, \mathrm{VB}$ starts decreasing with an increase in cutting speed from 30 to $50 \mathrm{~m} / \mathrm{min}$. However, at a higher cutting speed of $50 \mathrm{~mm} / \mathrm{min}$., VB increases significantly with an increase in DOC from 0.20 to $0.40 \mathrm{~mm}$ because of ploughing effect developed at the cutting zone which gives higher cutting forces. In addition, ploughing effect produces more stresses and load on cutting tool edges, resulting in aggressive tool wear. Similar effects have been observed by Wang et al. [43] and Singh et al. [10] during milling of Inconel 182 and Inconel 718, respectively. Their outcomes revealed that the highest level of DOC results in maximum tool flank wear. Minimum tool flank wear is achieved at cutting speed $=50 \mathrm{~m} / \mathrm{min}$. and DOC $=0.2 \mathrm{~mm}$ as noticed in Figure 3 .

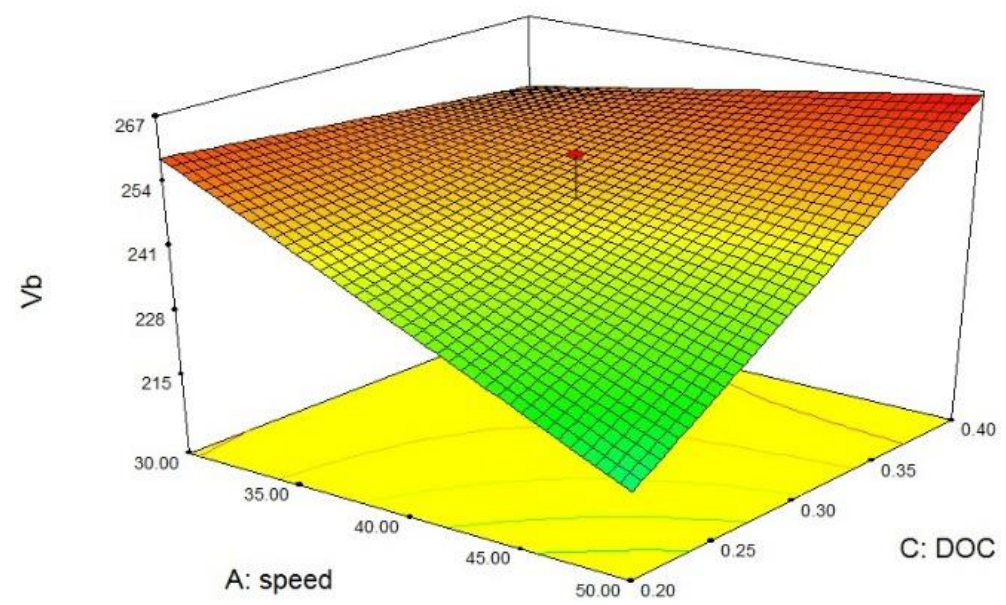

Figure 3. Influence of cutting speed and depth of cut (DOC) on VB.

\section{Optimisation of Machining Parameters}

RSM based desirability function optimisation was applied to minimise machined surface roughness $(\mathrm{Ra})$ and tool flank wear (VB). Optimal values of machining parameters have been observed as; cutting speed $=46.89 \mathrm{~m} / \mathrm{min}$, table feed rate $=0.05 \mathrm{~mm} /$ tooth and DOC $=0.2 \mathrm{~mm}$ with predicted tool flank wear $=191.741 \mu \mathrm{m}$ and surface roughness $=0.89$ $\mu \mathrm{m}$ at desirability level of 0.957 (refer to Table 8).

Table 8. Optimal solutions.

\begin{tabular}{lccccccc}
\hline No. & $\begin{array}{c}\text { Cutting } \\
\text { speed } \\
(\mathrm{m} / \mathrm{min})\end{array}$ & $\begin{array}{c}\text { Table feed } \\
(\mathrm{mm} / \text { tooth })\end{array}$ & $\begin{array}{c}\text { Depth } \\
\text { of cut } \\
(\mathrm{mm})\end{array}$ & $\begin{array}{c}\mathrm{Ra} \\
(\mu \mathrm{m})\end{array}$ & $\begin{array}{c}\mathrm{VB} \\
(\mu \mathrm{m})\end{array}$ & Desirability & \\
\hline 1 & 46.89 & 0.05 & 0.2 & 0.89 & 191.741 & 0.956 & Selected \\
2 & 46.79 & 0.05 & 0.2 & 0.89 & 192.287 & 0.953 & \\
3 & 46.7 & 0.05 & 0.2 & 0.89 & 194.783 & 0.936 & \\
4 & 48.82 & 0.05 & 0.2 & 0.9699 & 187.565 & 0.915 & \\
5 & 49.61 & 0.05 & 0.2 & 1.0076 & 185.867 & 0.891 & \\
6 & 37.41 & 0.05 & 0.2 & 0.7565 & 212.223 & 0.812 & \\
7 & 38.6 & 0.05 & 0.27 & 0.89 & 215.516 & 0.786 & \\
\hline
\end{tabular}

\section{Face Milling Under NMQL Conditions}

In the second design phase, experiments were conducted at optimal parameters (Table 8: 
obtained in first stage pure MQL experimentation) under NMQL environment with different weight concentrations of MWCNT in base oil: $0.50,0.75,1,1.25$ and 1.5 wt. \% to compare face milling performance of Inconel 625 under MQL and NMQL on the basis of $\mathrm{Ra}$ and $\mathrm{VB}$ match. Each experiment was repeated (3 times) under different concentration to check any experimental machining errors.

The experimental results revealed that at $0.05 \%$ weight concentration, NMQL provides high surface roughness and poor tool life. However, with an increase in weight concentration of nanoparticles in the base oil, machining performance improves and at 1 $\%$ wt. concentration, minimum VB and Ra were reported as depicted in Figure 4 . The results show with an increased percentage of nanoparticles up to a certain limit, the thermal conductivity of base fluid increases and it also provides the rolling effect to reduce friction between tool-work interfaces, thereby results in lesser tool flank wear during milling of Inconel 625 at 1\% wt. the concentration of MWCNT. However, when weight concentration of nanoparticles is increased further, from $1 \%$ to $1.5 \%$, tool flank wear and surface roughness show an increasing trend. This is due to the fact that, the higher weight percentage of nanoparticles in soybean oil, increases its density which reduces nano-fluid flow-ability in the cutting zone, therefore lesser quantity of nano-fluid reaches in the cutting zone. Similar findings have been noticed by Hegab et al. [44] during machining of Inconel 718 with MQL using MWCNT and Al2O3 nanoparticles. The 1\% weight concentration of MWCNT shows a reduction in surface roughness by $17.33 \%$ and tool flank wear by $10.34 \%$ compared to pure MQL as shown in Figure 4.

Experiments were performed to investigate the performance of pure MQL and NMQL (1 \% wt.) under different machining parameters (Table 9) and their results are compared on the basis of Ra and VB. Results reveal the superiority of NMQL over MQL by providing $17.33 \%$ better surface finish and $11.48 \%$ lower tool flank wear compared to pure MQL. Vasu and Reddy [45] noticed similar results during machining of Inconel 600. Their findings showed that cutting forces, surface roughness, the temperature of cutting zone and wear of tool are significantly reduced under nanoparticle (Al2O3) MQL machining compared to simple MQL machining. Hegab et al. [44] reported superiorly of NMQL (MWCNT and Al2O3 nanoparticles) over pure MQL on basis of VB and Ra during machining of Inconel 718. Similarly, Uysal et al. [46] experienced lesser tool wear and higher surface finish using MoS2 nanoparticles with MQL compare to pure MQL during milling of stainless steel (AISI 420).

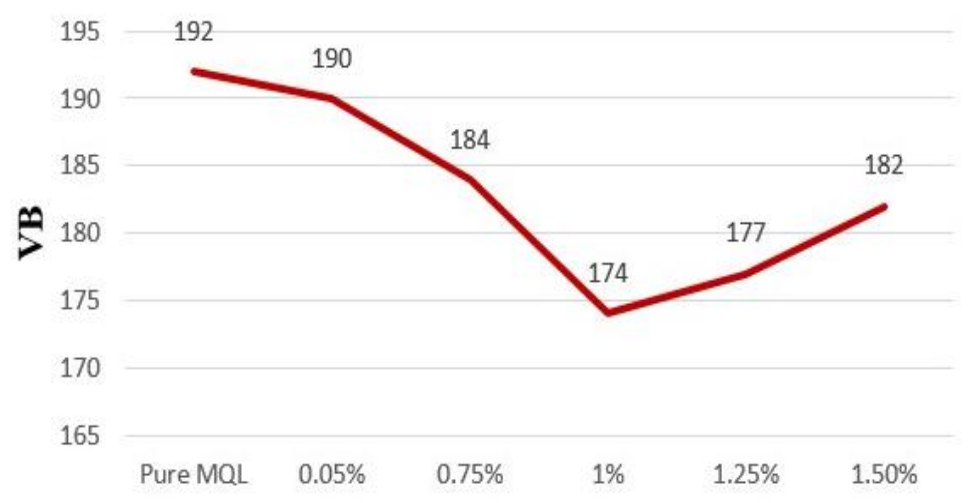

(a) 


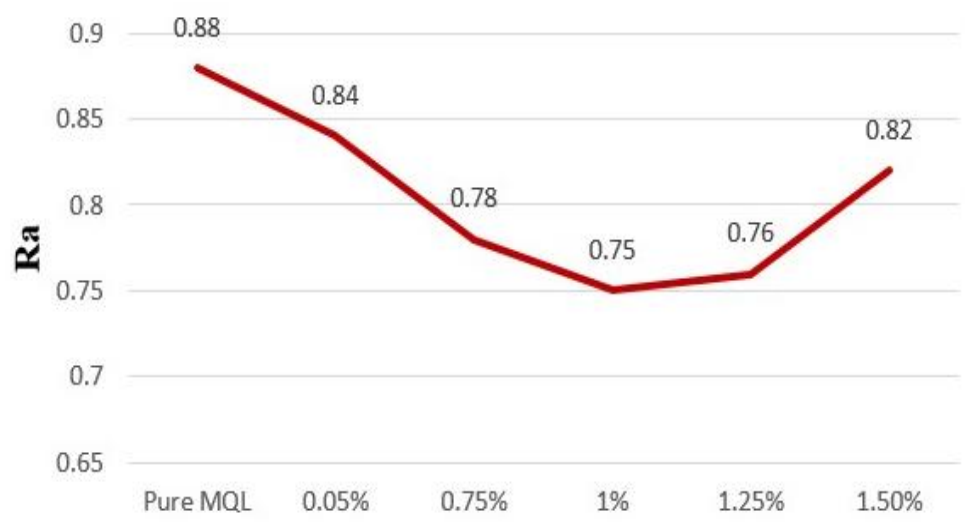

(b)

Figure 4. Effect of different wt. \% of MWCNTs on (a) VB and; (b) Ra.

Table 9. Comparison of pure MQL and NMQL under different machining parameter at $1 \mathrm{wt}$. $\%$ of MWCNTs.

\begin{tabular}{|c|c|c|c|c|c|c|c|c|c|}
\hline \multirow[t]{2}{*}{$\begin{array}{l}\text { S. } \\
\text { No }\end{array}$} & \multicolumn{3}{|c|}{ Machining Parameters } & \multicolumn{2}{|c|}{$\begin{array}{l}\text { NMQL } \\
(1 \mathrm{wt} . \%)\end{array}$} & \multicolumn{2}{|c|}{ Pure MQL } & \multicolumn{2}{|c|}{$\begin{array}{c}\text { Improvement } \\
\text { NMQL vs Pure MQL }\end{array}$} \\
\hline & $\begin{array}{c}\text { Cutting } \\
\text { speed }\end{array}$ & $\begin{array}{l}\text { Table } \\
\text { feed }\end{array}$ & DOC & $\mathrm{Ra}$ & VB & $\mathrm{Ra}$ & VB & $\mathrm{Ra} \%$ & $\mathrm{VB} \%$ \\
\hline 1 & 30 & 0.5 & 0.2 & 0.83 & 210 & 0.96 & 225 & 15.6627 & 7.14286 \\
\hline 2 & 47 & 0.5 & 0.2 & 0.75 & 174 & 0.88 & 192 & 17.3333 & 10.3448 \\
\hline 3 & 50 & 0.5 & 0.2 & 0.91 & 172 & 1.02 & 185 & 12.0879 & 7.55814 \\
\hline 4 & 47 & 0.075 & 0.2 & 0.97 & 209 & 1.04 & 222 & 7.21649 & 6.2201 \\
\hline 5 & 47 & 0.1 & 0.2 & 1.02 & 173 & 1.19 & 190 & 16.6667 & 9.82659 \\
\hline 6 & 47 & 0.5 & 0.3 & 0.96 & 196 & 1.09 & 212 & 13.5417 & 8.16327 \\
\hline 7 & 47 & 0.5 & 0.4 & 1.1 & 209 & 1.2 & 233 & 9.09091 & 11.4833 \\
\hline
\end{tabular}

\section{CONCLUSION}

In the present study, the potential of MQL and NMQL in face milling of Inconel 625 has been experimentally investigated and performance of MQL and NMQL environments has also been compared. Following conclusions can be made based on the experimental results:

i. NMQL provides green machining by maintaining dry and pollution-free working area.

ii. Results reveal the superiority of NMQL over MQL by providing $17.33 \%$ better surface finish and $11.48 \%$ lesser tool flank wear compared to pure MQL.

iii. The $1 \%$ weight concentration of MWCNT provides minimum tool wear of $174 \mu \mathrm{m}$ and surface roughness of $0.75 \mu \mathrm{m}$, compared to other weight concentration of nanoparticles.

iv. Optimum cutting conditions for face milling of Inconel 625 are found as: cutting speed $=47 \mathrm{~m} / \mathrm{min}$, table feed rate $=0.05 \mathrm{~mm} /$ tooth and depth of cut $=0.20 \mathrm{~mm}$ for surface roughness of $0.89 \mu \mathrm{m}$ and tool flank wear of $191.74 \mu \mathrm{m}$ under MQL conditions. 


\section{REFERENCES}

[1] Kursuncu B and Yaras A. Assessment of the effect of borax and boric acid additives in cutting fluids on milling of AISI O2 using MQL system. The International Journal of Advanced Manufacturing Technology 2018; 95(5-8): 2005-2013.

[2] Tai BL, Stephenson DA, Furness RJ, Shih AJ. Minimum quantity lubrication (MQL) in automotive powertrain machining. Procedia CIRP 2014; 14: 523-528.

[3] Oliveira GDP, Fonseca MC, Araujo AC. Analysis of residual stress and cutting force in end milling of Inconel 718 using conventional flood cooling and minimum quantity lubrication. The International Journal of Advanced Manufacturing Technology 2017; 92(9-12): 3265-3272.

[4] Singh P, Singh J, Dureja JS, Singh T, Dogra M, Bhatti MS. Performance evaluation of milling of Inconel-625 under minimum quantity lubrication. Journal for Manufacturing Science and Production 2016; 16(1): 61-68.

[5] Singh T, Singh P, Dureja JS, Dogra M, Singh H, Bhatti MS. A review of near dry machining/minimum quantity lubrication machining of difficult to machine alloys. International journal of Machining and Machinability of Materials 2016; 18(3): 213-251.

[6] Patel JK, Raval GV, K P. Study of cutting forces, surface roughness and tool wear on end milling of Inconel 625 in dry and MQL conditions. Proceedings of 6th International \& 27th All India Manufacturing Technology, Design and Research Conference (AIMTDR-2016) 2016.

[7] Shokrani A, Dhokia V, Newman ST. Environmentally conscious machining of difficult-to-machine materials with regard to cutting fluids. International Journal of Machine Tools and Manufacture 2012; 57: 83-101.

[8] Amrita M, Srikant RR, Sitaramaraju AV. Performance evaluation of nano graphite based cutting fluid in machining process. Materials and Manufacturing Processes 2014; 29(5): 600-605.

[9] Sun J, Wong Y, Rahman M, Wang Z, Neo K, Tan C, Onozuka H. Effects of coolant supply methods and cutting conditions on tool life in end milling titanium alloy. Machining Science and Technology 2006; 10(3): 355-370.

[10] Singh G, Gupta MK, Mia M, Sharma VS. Modeling and optimisation of tool wear in MQL-assisted milling of Inconel 718 superalloy using evolutionary techniques. The International Journal of Advanced Manufacturing Technology 2018; 97(1-4): 481-494.

[11] Werda S, Duchosal A, Quilliec G L, Morandeau A, Leroy R. Minimum quantity lubrication advantages when applied to insert flank face in milling. The International Journal of Advanced Manufacturing Technology 2017.

[12] Park KH, Yang GD, Lee DY. Tool wear analysis on coated and uncoated carbide tools in inconel machining. International Journal of Precision Engineering and Manufacturing 2015; 16(7): 1639-1645.

[13] Gupta MK and Sood PK. Surface roughness measurements in NFMQL assisted turning of titanium alloys: An optimisation approach. Friction 2017; 5(2): 155170.

[14] Liao YS, Liao CH, Lin HM. Study of oil-water ratio and flow rate of MQL fluid in high speed milling of Inconel 718. International Journal of Precision Engineering and Manufacturing 2017; 18(2): 257-262. 
[15] Zhang X, Xu H, Wang J, Ye X, Lei W, Xue M, Tang H, Li C. Synthesis of ultrathin WS2 nanosheets and their tribological properties as lubricant additives. Nanoscale Res Lett 2016; 11(1): 442.

[16] Sharma AK, Tiwari AK, Dixit AR. Progress of nanofluid application in machining: a review. Materials and Manufacturing Processes 2015; 30(7): 813828.

[17] Vajjha RS and Das DK. A review and analysis on influence of temperature and concentration of nanofluids on thermophysical properties, heat transfer and pumping power. International Journal of Heat and Mass Transfer 2012; 55(1516): 4063-4078.

[18] Choi S, Zhang Z, Yu W, Lockwood F, Grulke E. Anomalous thermal conductivity enhancement in nanotube suspensions. Applied Physics Letters 2001; 79(14): 2252-2254.

[19] Setti D, Sinha MK, Ghosh S, Rao PV. Performance evaluation of Ti-6Al-4V grinding using chip formation and coefficient of friction under the influence of nanofluids. International Journal of Machine Tools and Manufacture 2015; 88: 237-248.

[20] Eltaggaz A, Hegab H, Deiab I, Kishawy H. Hybrid nano-fluid-minimum quantity lubrication strategy for machining austempered ductile iron (ADI). International Journal on Interactive Design and Manufacturing (IJIDeM) 2018; 12(4): 12731281.

[21] Reddy NSK and Rao PV. Experimental investigation to study the effect of solid lubricants on cutting forces and surface quality in end milling. International Journal of Machine Tools and Manufacture 2006; 46(2): 189-198.

[22] Khandekar S, Ravi SM, Agnihotri V, Ramkumar J. Nano-cutting fluid for enhancement of metal cutting performance. Materials and Manufacturing Processes 2012; 27(9): 963-967.

[23] Sharma AK, Katiyar JK, Bhaumik S, Roy S. Influence of alumina/MWCNT hybrid nanoparticle additives on tribological properties of lubricants in turning operations. Friction 2018.

[24] Rahmati B, Sarhan AA, Sayuti M. Morphology of surface generated by end milling AL6061-T6 using molybdenum disulfide (MoS2) nanolubrication in end milling machining. Journal of Cleaner Production 2014; 66: 685-691.

[25] Rao SN, Satyanarayana B, Venkatasubbaiah K. Experimental estimation of tool wear and cutting temperatures in MQL using cutting fluids with CNT inclusion. International Journal of Engineering Science and Technology 2011; 3(4).

[26] Krishna P, Srikant R, Parimala N. Experimental investigation on properties and machining performance of CNT suspended vegetable oil nanofluids. International Journal of Automotive and Mechanical Engineering 2018; 15(4): 5957-5975.

[27] Hegab H, Umer U, Deiab I, Kishawy H. Performance evaluation of Ti-6Al-4V machining using nano-cutting fluids under minimum quantity lubrication. The International Journal of Advanced Manufacturing Technology 2018; 95(9-12): 4229-4241.

[28] Singh T, Dureja JS, Dogra M, Bhatti MS. Environment friendly machining of inconel 625 under nano-fluid minimum quantity lubrication (NMQL). International Journal of Precision Engineering and Manufacturing 2018; 19(11): 1689-1697.

[29] Singh T, Dureja JS, Dogra M, Bhatti MS. Machining Performance Investigation of AISI 304 Austenitic Stainless Steel under Different Turning Environments. 
International Journal of Automotive and Mechanical Engineering 2018; 15(4): 5837-5862.

[30] Singh P, Dureja JS, Singh H, Bhatti M. Performance evaluation of coated carbide tool during face milling of AISI 304 under different cutting environments. Materials Research Express 2019; 6(5): 056546.

[31] Sharma AK, Singh RK, Dixit AR, Tiwari AK. Characterization and experimental investigation of A12O3 nanoparticle based cutting fluid in turning of AISI 1040 steel under minimum quantity lubrication (MQL). Materials Today: Proceedings 2016; 3(6): 1899-1906.

[32] Minh DT, The LT, Bao NT. Performance of $\mathrm{Al}_{2} \mathrm{O}_{3}$ nanofluids in minimum quantity lubrication in hard milling of $60 \mathrm{Si} 2 \mathrm{Mn}$ steel using cemented carbide tools. Advances in Mechanical Engineering 2017; 9(7).

[33] Najiha MS and Rahman MM. Experimental investigation of flank wear in end milling of aluminum alloy with water-based $\mathrm{TiO}_{2}$ nanofluid lubricant in minimum quantity lubrication technique. The International Journal of Advanced Manufacturing Technology 2016; 86(9-12): 2527-2537.

[34] Rodrigues MA, Hassui A, Silva RHLD, Loureiro D. Tool life and wear mechanisms during Alloy 625 face milling. The International Journal of Advanced Manufacturing Technology 2016; 85(5-8): 1439-1448.

[35] Prasad KS, Rao CS, Rao DN. Optimisation of fusion zone grain size, hardness, and ultimate tensile strength of pulsed current micro plasma arc welded Inconel 625 sheets using genetic algorithm. The International Journal of Advanced Manufacturing Technology 2015; 85(9-12): 2287-2295.

[36] Zhu D, Zhang X, Ding H. Tool wear characteristics in machining of nickel-based superalloys. International Journal of Machine Tools and Manufacture 2013; 64: 60-77.

[37] Sonawane HA and Joshi SS. Modeling of machined surface quality in high-speed ball-end milling of Inconel-718 thin cantilevers. The International Journal of Advanced Manufacturing Technology 2015; 78(9-12): 1751-1768.

[38] Dureja, JS and Gupta VK. Design optimisation of flank wear and surface roughness for CBN-TiN tools during dry hard turning of hot work die steel. International Journal of Machining and Machinability of Materials 2010; 7(1/2): 129-147.

[39] Gupta MK, Sood P, Sharma VS. Investigations on surface roughness measurement in minimum quantity lubrication turning of titanium alloys using response surface methodology and Box-Cox transformation. Journal for Manufacturing Science and Production 2016; 16(2): 75-88.

[40] Bin Z, Chen M, Huang C, Q. A study on surface damages caused by turning NiCr20TiAl nickel-based alloy. Journal of materials processing technology 2009; 209(17): 5802-5809.

[41] Lu X, Wang F, Wang X, Lu Y, Si L. A Surface roughness prediction model using response surface methodology in micro-milling Inconel 718. International Journal of Machining and Machinability of Materials 2017; 19(3): 230-245.

[42] Yazid MZA, CheHaron CH, Ghani JA, Ibrahim GA, Said AYM. Surface integrity of Inconel 718 when finish turning with PVD coated carbide tool under MQL. Procedia Engineering 2011; 19: 396-401.

[43] Wang C, Ming W, Chen M. Milling tool's flank wear prediction by temperature dependent wear mechanism determination when machining Inconel 182 overlays. Tribology International 2016; 104: 140-156. 
[44] Hegab H, Darras B, Kishawy HA. Sustainability assessment of machining with nano-cutting fluids. procedia Manufacturing 2018; 26: 245-254.

[45] Vasu V and Reddy PK. Effect of minimum quantity lubrication with $\mathrm{Al}_{2} \mathrm{O}_{3}$ nanoparticles on surface roughness, tool wear and temperature dissipation in machining Inconel 600 alloy. Proceedings of the Institution of Mechanical Engineers, Part N: Journal of Nanoengineering and Nanosystems 2011; 225(1): 3-16.

[46] Uysal A, DF, Altan E. Applying minimum quantity lubrication (MQL) method on milling of martensitic stainless steel by using nano $\mathrm{MoS}_{2}$ reinforced vegetable cutting fluid. Procedia - Social and Behavioral Sciences 2015; 195: 2742-2747. 